\title{
Current state of innovative development of Russian wine
}

\author{
Angelika Efremova*, Elena Shevchenko, Natalia Oshovskaya, Anna Kaminskaya, and \\ Anna Finogentova
}

Federal State Autonomous Educational Institution of Higher Education "Crimean Federal University named V.I. Vernadsky", 259018, 4 Vernadsky Avenue, Simferopol, Republic of Crimea, Russian Federation

\begin{abstract}
The article provides a retrospective study of the development of the innovative state of the country's wine industry. The negative moments of the past and prospects for further development are indicated. The main southern regions of Russia, which are famous for the cultivation of grapes and the production of wine, are considered. A comparative assessment of the wine-making industry of the southern regions of Russia with neighboring regions is carried out. The characteristics of the largest winemaking enterprises of the Republic of Crimea, Krasnodar Territory and Rostov Region are given. The dynamics of wine production in the Republic of Crimea for the period 2013-2019 is given. The analysis of the results of the impact of scientific and technological progress, namely: the work of innovation centers aimed at training qualified personnel, winemakers, which will help improve the results of the economic activities of winemaking enterprises. Examples of such work in European countries are given.
\end{abstract}

\section{Introduction}

In Russia, in other fashion and in particular wine has always played an important role in life. Russia can be called countries with a long history of wine-making, and this story is known as the ups, so and falls. On the territory of Russia, winemaking existed already in the days of Ancient Greece, namely on the territory of the peninsula and the Crimea and the Taman Peninsula. The wine industry had a rapid development in the Soviet Union, but it was in the USSR, the industry received a huge loss to the anti-alcohol oh Campania M. Gorbachev. It was only in the 2000s that winemaking received a gradual development, which still needs investment. But under modern conditions it is impossible to imagine the development of any industry without innovation. In this regard, this article will analyze the current state of the wine industry in Russia using the example of the largest regions representatives of wine production and grape growing.

\footnotetext{
* Corresponding author: ser_efrem@mail.ru
} 


\section{Materials and Methods}

To write this article, research methods and analysis of statistical information and various scientific sources were used. The research was carried out using the methods of generalization, systematization and structuring of the material.

\section{Results and Discussion}

According to the data of the Federal State Statistics Service of Russia, in 2019 the area of vine plantations in farms of all categories was 95,900 hectares. The southern regions of Russia are distinguished by a favorable climate for the cultivation of grapes for further use in the wine industry. One of the largest regions in terms of vineyard area is the Krasnodar Territory. As shown by the data of the Office for Viticulture and Wine Industry of the Ministry of Agriculture and Processing Industry of the Krasnodar Territory in 2020 the area of vineyards in this region amounted to 27,520 hectares, of which 20,600 hectares in fruitbearing age and 4500 hectares under table varieties.

In the Krasnodar Territory, the process of viticulture and engaged in more than 70 specialist companies, as well as around 150 small farms.

The South of Russia is famous for its traditional branches of the agro-industrial complex, one of the brightest representatives of which is winemaking and viticulture. A specific feature of this industry is a number of natural factors that have a direct impact on the cultivation of such a capricious culture as grapes. The terroir of southern Russia is diverse and unique for the cultivation of grapes and the production of wine. All wineries are equipped with powerful equipment, excellent human resources, and unique technologies for the production of this excellent drink. But at the same time, the wine industry is quite risky, due to the fact that it is directly dependent on the unpredictability of natural phenomena.

This paper will consider the main southern Russian regions that grow grapes and produce wine, namely: Krasnodar Territory, Republic of Crimea, Sevastopol and Rostov Region. Note that the Republic of Crimea is perhaps the most prominent representative in the production of grapes, since the Crimean lands and nature - terroir, have unique conditions for the cultivation of this culture and the production of unique wine.

On the territory of the Republic of Crimea, there are more than 100 wineries of primary, secondary and full cycle of production of various types of wine products. The largest companies are: LOD "Massandra", "NIViV "Magarach" RAS" plant "New World", JSC "Sun Valley", and so on. The city of Sevastopol is represented by Inkerman Vintage Wine Factory LLC. Also note that the area of vineyards in the Republic of Crimea is 50 thousand hectares, and in other regions only about 65 thousand hectares [1].

The Krasnodar Territory is represented by such large wine - making enterprises: JSC "Abrau-Dyurso", JSC "Fanagoria" and others.

The Rostov Region is represented by the Vedernikov Winery, the Tsimlyanskie Viny Winery, the Elbuzd Winery, and others.

According to Rosalkogolregulirovanie, in 2019, the Russian Federation produced \$ 328 million of still wines, which is $8 \%$ higher than the previous period, and $132 \mathrm{mln} 1$ sparkling wines $\mathrm{h}$ then $6 \%$ above 2018 . At the end of 2019 production of wine has increased for the first time in the last 4 years. At the same time, as noted in the wine competition is, Russian Wines Competition in 2020, during this period increased the production of red wines than white, which is $58 \%$ and $42 \%$, respectively.

Regarding the Republic of Crimea, it can be noted that the production of wine was in a jump-like dynamics (Fig. 1). 


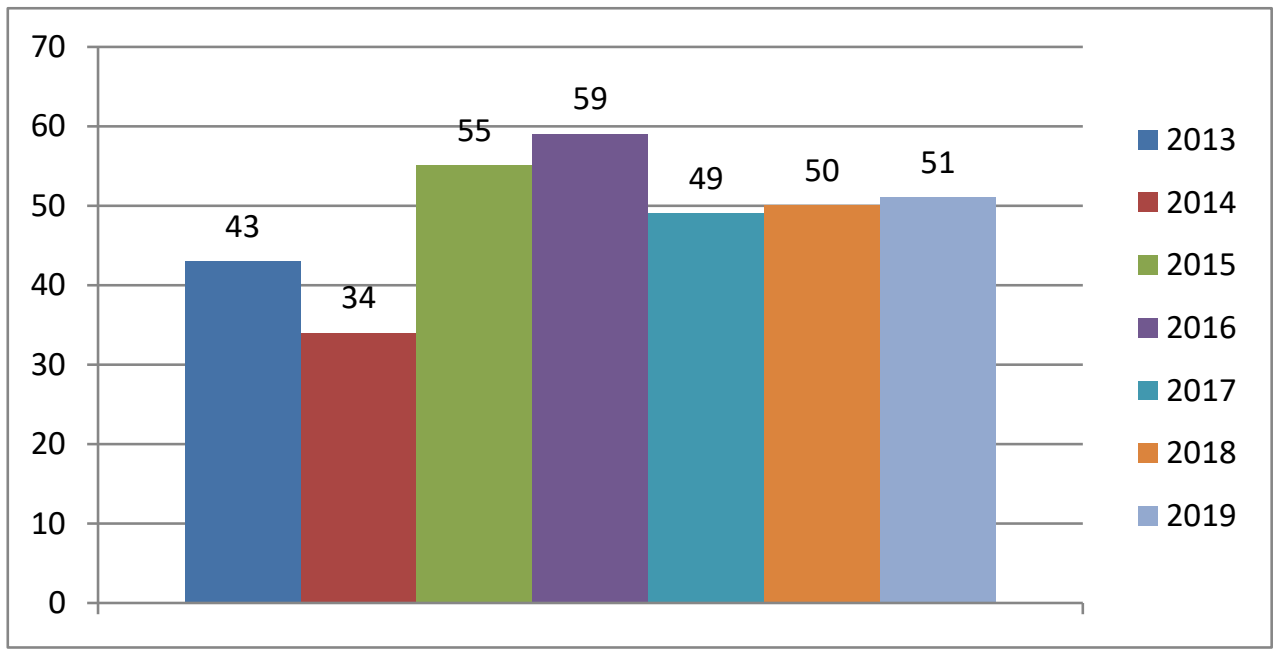

Fig. 1. Wine production in the Republic of Crimea for 2013-2019, million liters, [2].

This is due to many factors. First, the transition to the Russian legal field played a huge role. Entered the new norm $\mathrm{s}$ had some negative impact on the wineries. Even large enterprises were under attack. This was due to the installation and the EGAIS system, which was introduced to control production, it is quite expensive. Also, the reasons $\mathrm{s}$ become and Russian tax policy and certain specifics Russian winemaking technology. As a result of these innovations, most of the Crimean wines received the status of "wine drink".

The result was a high dynamics of table wine production in the Republic of Crimea, which manifests itself as rather unstable, namely: there is an alternation of decline and growth with large deviations. So, in 2014 against the backdrop of the annexation of the production of wine production has decreased by $20 \%$ (43 to 34.4 million liters). The reasons for this was the lack of payment of vine-growers, grape farms were unable to pay off the loan because of high interest rates, which also lost the Ukrainian Wed dstv to I plant protection and pest management. At the same time, the harvest of grapes in the same year decreased by $26 \%$ - to 70 thousand tons t.

However, in the next year rate of production and wine grown to 55 million liters, and in 2016 - up to 59 million. 1. This rise occurred due to filling of the Crimean wineries wine production of a cheap wine, which were massively Head ezeny in the Republic of Crimea [3].

To our great regret, in all subsequent years, there was a tendency for a decline in the bottling of real, high-quality Crimean wine, it is becoming less and less due to the shortage of high-quality raw materials. At the same time, the volume of wines of dubious quality is growing. Also, there is no growth in the production of still wines, in comparison with 2013 only $16 \%$ more was produced [4].

Figure 2 shows the dynamics of wine production in the Republic of Crimea for the period 2013-2019. 


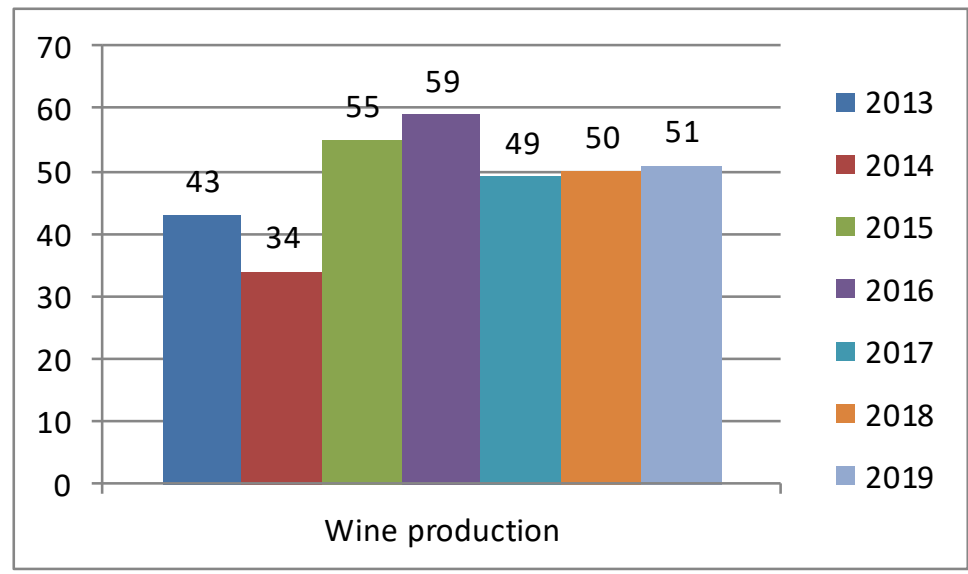

Fig. 2. Wine production in the Republic of Crimea for the period 2013-2019, mln. liters, [5].

As the practice of winemaking shows, by the beginning of 2021 of 100 items Crimean wine only $20 \%$ made from grapes which are grown peninsula. At the same time, the wine material imported to the peninsula cannot be called high-quality, and the high-quality wine material is too expensive, so it is not imported. Tanchors imported unmarketable wine material, which was then, and poured on the Crimean plants.

The cost of such a product is about 100 rubles, in stores it is sold for 150-200 rubles. The quality leaves much to be desired, and, unfortunately, among the tourists arriving there is an opinion that these are the Crimean wines $[6,7]$.

Note that both autochthonous and international grape varieties are cultivated in Russia. As shown in 2020. Wynne first competition of Russian Wines Competition in 2020, the most popular and international and varieties and grapes are : white varieties - Aligote, family Muscat, Pinot Blanc, Riesling, Sauvignon Blanc, Chardonnay; black varieties Cabernet Sauvignon, Merlot, Pinot Noir. By popular autochthonous th grade s are : white varieties - Kokur white, Rkatsiteli , Sary Pandas, Sibirkovy; black varieties - Bastardo Magarachsky, Golubok , Kefesia, Krasnostop Zolotovsky, Saperavi , Tsimlyansky Black [8].

Regarding the development of viticulture in Russia, it can be noted that it takes place with the active support of the state. For these purposes, according to the Department for Viticulture and Wine Industry of the Ministry of Agriculture and Processing Industry of the Krasnodar Territory, in 2019, 1,037.1 million rubles were allocated rubles, including from the regional budget 325.7 million rubles, from the federal - 711.4 million rubles. These funds were used for planting vineyards, installing trellises and maintenance work - 937.1 million rubles, for the development of nursery growing and installation of drip irrigation 100.0 million rubles [9].

With the aim of developing the wine industry and introducing innovative technologies, the country's traveling educational institutions are constantly training highly qualified personnel for this industry. These universities are the Kuban State Agrarian University, which is one-quarter to them of the recognized leaders of higher agricultural education in Russia, the largest in the Southern Federal District, the center of science, education and innovation; Russian State Agrarian University - Moscow Agricultural Academy KA Timiryazev, over 200,000 specialists have been trained within the walls of the academy for a century and a half.

Since the Republic of Crimea is the main and outstanding representative of winemaking in Russia, we will use its example to consider the innovative development of this field of activity. As history shows, at the end of the last century began the collapse of the Scientific 
and Technical oh areas, which is etsya important element of the innovation system of the region. Run it this sphere was a 6 industrial design and technological institutes and 10 experimental stations and departments in different directions, which are provided, and the introduction of innovative developments in production. Under an innovative system in Russia means the totality of subjects and objects, which interact so in the creation and sale of products, as well as to realize so their activities under the relevant state policy [10]. In this context, talking about the future of innovation $\mathrm{m}$ development and the region, it is necessary to provide for the introduction of the latest high-performance technoogies in all spheres s agricultural production, further expansion of the bio- and organic farming in order to obtain clean food. When reviving the storage and processing of agricultural products, it is necessary to take into account modern methods and. It is also necessary to provide for a diverse $\mathrm{x}$ forms of gardening, expand ix productions and processing and grapes in small farms, cooperatives, as well as on personal garden plots.

But the further development of any industry, especially winemaking, in modern conditions of transformation and development of science, it is impossible to imagine without the effective use of scientific potential. At this stage, more than ever it is important to refer to the science, because without it is impossible to imagine defined ix is optimum the option and the development industry or an individual farm. Only a scientific approach is able to predict events and situations in certain conditions. To date, the Republic of Crimea is essential to develop a scientific substantiation of the second strategy and defining yayuschey long-term goals, objectives and key solutions. The development of such a scientifically based strategy will make it possible to achieve ecological improvement of the peninsula's agrosphere, increase the level of food security and agricultural sustainability. This approach will ensure the expansion of production, restore normal sostojani I environment, createconditions for the restoration and protection of water resources.

\section{Conclusion}

The revival of scientific and technical second spheres s can be represented on a network of business incubators, technology transfer centers, technology parks, innovation technological complexes and the like. At some wineries of the Crimea, there are excellent conditions for accommodation Agrotechnologicals park s, which can be a good platform for testing and introduction of new developments in the grape production. This process is impossible without the involvement of scientific institutions and universities, this approach will provide an opportunity to provide the leading functions of the regional innovation system. The scientific approach will make it possible to carry out such activities: the creation of scientific centers in order to access the necessary scientific information, the creation of analytical centers, information and others, which are necessary to promote innovation. It is also extremely necessary to organize centers for the training of scientific personnel in the field of innovation management, technology audit and other research areas. We also note that the necessary event is the provision of services on intellectual property at the scientific level, the organization of the process of standardization and certification in the field of production, finance, investment and management.

At the same time, we note that the new innovative first approach requires the preparation of special tools to activate the corresponding processes. Priority is administration e above regional strategy in agriculture. Example of this approach can take the experience of the European Union. Having determined that the economies of some countries has become less competitive by comparison the United States and Japan, they began to take measures in the early 1990s. As a result, the European Commission has developed a number of policy documents. Innovation took the leading role in this program, which led to unexpected results: enterprises in many regions began to achieve success in 
their economic cooperation and development. Also during this period, the EU countries began to actively develop programs to increase the innovative development of the economy. In 2000, the Council of Europe approved the Lisbon Strategy. In accordance with this strategy, the European Union was to become a more competitive and dynamic economy in the world. This development is due on was on serve as an answer to globalization, the development of other countries, unemployment, and the economic slowdown in the Old World. One of the four pillars of this strategy, in addition to liberalization, entrepreneurship and social cohesion, has been innovation, leading, along with the development of the information society, to the creation of a knowledge-based economy.

In conclusion, we note that in creating and in the Republic of Crimea, regional innovation systems, as well as the use of e all the existing tools allow agribusiness to fully realize the existing potential. The gradual introduction of the innovation system and the implementation of the tasks will increase the level of employment, as well as Contributing uet sustainable development of territories.

\section{References}

1. Review of the Russian alcoholic beverages market. Analytical Center for the Government of the Russian Federation (IV quarter 2020) https://ac.gov.ru/uploads/2Publications/alcogol/al\%D1\%810.2020.4.pdf

2. Analysis of the wine market in Russia Report BusinesStat https://marketing.rbc.ru/articles/11298/

3. Winemakers are working on import substitution, Information and analytical portal Best4service URL: http://journal.best4service.ru/vinodely

4. The concept of development of viticulture and winemaking in the Russian for the period 2016-2020 and the planning period until 2025 Russian government portal, URL: http://government.ru/rugovclassifier/718/events

5. E.A. Matushevskaya, A.V. Ogilba, Dynamics and prospects for the development of the wine industry in the Russian Federation, Topical issues of law, economics and management. Collection of articles of the $V$ international scientific and practical conference, 256-262 (Penza, Science and Education, 2016)

6. The new law on " import substitution " of wine can reduce the share of Russian wines KV Information Agency: news and analytics from 19.01.2020. URL: https://rossaprimavera.ru/feed/news

7. A.K. Radjabov, N.P. Mishurov, T.A. Shchegolikhina, State and prospects for the development of viticulture, including nursery: a scientific and analytical review, 92 (M., Federal State Budgetary Scientific Institution " Rosinformagrotech" 2019)

8. Development and prospects of the wine market in Russia 2019 Portal about the food industry SPHERE, URL: https://sfera.fm/articles / konditerskaya /

9. The flourishing of viticulture in the Russian Federation, Materials of the information and analytical site from 11.07.2019 https://aftershock.news/770146

10. Russia in Figures 2018 Online stat. c bornik. URL: https://nangs.org/analytics/ rosstat.pdf 